\title{
An Extended Twin-Pedigree Study of Neuroticism in the Netherlands Twin Register
}

\author{
Dorret I. Boomsma ${ }^{1,2,3}$ (다 $\cdot$ Quinta Helmer $^{1} \cdot$ Harold A. Nieuwboer $^{1} \cdot$ Jouke Jan Hottenga $^{1,2} \cdot$ Marleen H. de Moor $^{2,4}$. \\ Stéphanie M. van den Berg ${ }^{5}$ - Gareth E. Davies ${ }^{3}$. Jacqueline M. Vink ${ }^{6}$ Maarten J. Schouten ${ }^{1}$ - Conor V. Dolan ${ }^{1,2}$. \\ Gonneke Willemsen $^{1,2} \cdot$ Meike Bartels ${ }^{1,2}$ - Toos C. E. M. van Beijsterveldt ${ }^{1}$ - Lannie Ligthart ${ }^{1,2} \cdot$ Eco J. de Geus $^{1,2}$
}

Received: 1 April 2017 / Accepted: 23 September 2017 / Published online: 17 October 2017

(c) The Author(s) 2017. This article is an open access publication

\begin{abstract}
For the participants in the Netherlands Twin Register (NTR) we constructed the extended pedigrees which specify all relations among nuclear and larger twin families in the register. A total of 253,015 subjects from 58,645 families were linked to each other, to the degree that we had information on the relations among participants. We describe the algorithm that was applied to construct the pedigrees. For $>30,000$ adolescent and adult NTR participants data were available on harmonized neuroticism scores. We analyzed these data in the Mendel software package (Lange et al., Bioinformatics 29(12):1568-1570, 2013) to estimate the contributions of additive and nonadditive genetic factors. In contrast to much of the earlier work based on twin data rather than on extended pedigrees, we could also estimate the contribution of shared household effects in the presence of non-additive genetic factors. The estimated broad-sense heritability of neuroticism was $47 \%$,
\end{abstract}

Edited by Deborah Finkel.

Dorret I. Boomsma

di.boomsma@vu.nl

$1 \quad$ Netherlands Twin Register, Department of Biological Psychology, Vrije Universiteit Amsterdam, Van der Boechorststraat 1, 1081 BT Amsterdam, The Netherlands

2 EMGO+ Institute for Health and Care Research, Vrije Universiteit Amsterdam, Amsterdam, The Netherlands

3 Avera Institute for Human Genetics, Sioux Falls, USA

4 Clinical Child and Family Studies, Vrije Universiteit Amsterdam, Amsterdam, The Netherlands

5 Department of Research Methodology, Measurement, and Data Analysis, University of Twente, Enschede, The Netherlands

6 Behavioural Science Institute, Radboud University, Nijmegen, The Netherlands with almost equal contributions of additive and non-additive (dominance) genetic factors. A shared household effect explained $13 \%$ and unique environmental factors explained the remaining $40 \%$ of the variance in neuroticism.

Keywords Pedigree analysis - Neuroticism - Heritability . Genetic non-additivity $\cdot$ Shared household effect .

Extended twin-family design $\cdot$ Netherlands Twin Register

\section{Introduction}

Like many large twin registries worldwide, The Netherlands Twin Register (NTR) not only recruits twins, but also their family members, including parents, siblings, spouses and offspring of twins. This has led to a database with roughly equal proportions of participants who are and who are not twins. In genetic studies, the simultaneous analysis of all data from extended twin families can offer substantial gains in statistical power, when, for example, estimating non-additive genetic components of variance or when considering the effects of a shared family environment (Posthuma and Boomsma 2000; Rebollo and Boomsma 2006a, b; Keller et al. 2010). Here, we analyzed a large dataset on neuroticism from twins, their biological relatives and nonbiological family members, including spouses ( $\mathrm{N}>30,000$ subjects), after constructing the extended pedigrees (see "Methods"), that link all nuclear families from the Netherlands Twin Register to each other within larger pedigrees. Neuroticism questionnaires were completed by twins and their spouses, their parents and siblings in a number of NTR projects (e.g. Middeldorp et al. 2007; Nivard et al. 2015). Two different personality instruments were used and data for neuroticism were harmonized using an item-response theory (IRT) approach (van den Berg et al. 2007, 2014). 
Van den Berg et al. (2014) applied IRT to neuroticism data from a large number of international cohorts with twin data (total $\mathrm{N}=29,496$ twin pairs from six cohorts) and estimated the heritability of neuroticism at $48 \%$ with roughly equal contributions of additive and non-additive genetic factors. This estimate closely resembled the estimate of $42 \%$ from a large meta-analysis of behavior genetic studies on personality including over 100,000 subjects (Vukasović and Bratko 2015). Moderator analyses in this meta-analysis indicated higher heritability estimates in twin studies (47\%) compared to family and adoption studies (22\%). Vukasović and Bratko (2015) attributed the difference in these estimates to nonadditive genetic effects, which contribute to resemblances of monozygotic twins and full siblings, but not to resemblance of other family members, with the exception of double first cousins (Weir et al. 2006). The contribution of shared environment to familial resemblance was not considered in the meta-analysis. Given data obtained in nuclear families (including twins), it is difficult to assess the importance of shared environment (Keller et al. 2010). Here we modeled neuroticism data from twins and their relatives in extensive pedigrees, which allowed estimation of both non-additive genetic and shared environmental effects.

In genetic covariance modeling, the specification of relationships among family members and the calculation of pedigree likelihoods given large and irregular pedigrees is not straightforward. Twin data are often analyzed in structural equation modeling (SEM) software, such as Mx, OpenMx, Mplus, or LISREL (Neale et al. 1994, 2016; Muthén et al. 2006; Jöreskog 1970). While these programs offer great flexibility in model specification, they are less well suited to the analysis of data from large and complex pedigrees. As an alternative, we used the Mendel software package (Lange et al. 2013) for genetic data analyses. We constructed and implemented an algorithm which took the NTR administrative database (Boomsma et al. 2008) as input and gave the larger pedigree structures in standard pedigree format as output to be used by software such as 'Mendel' (Lange et al. 2013) or 'Merlin' (Abecasis et al. 2002). The Mendel software constructs the genetic relations among pedigree members, e.g. sibling, cousins, aunt-niece, grandparent-grandchild etc., and estimates components of genetic covariance for any pair of relatives from the weighted combination of additive and dominance effects (Weiss 1993). The information required to reconstruct genetic relationships between individuals in a pedigree of any size is (1) a family identifier (ID) shared by all members of a pedigree, (2) an individual identifier, (3) a link to the parents of that individual, (4) and the individual's sex, appropriately coded. Genetic relations among members of a pedigree who share the same family ID are traced by specifying the parents of individuals. A pedigree is defined by a set of related individuals, in which each individual either is either a founder (no parents in the pedigree) or not. Both parents of non-founding individual are identified within the pedigree. Additionally, extra fields can be added to indicate the presence of monozygotic twins (or higher-order multiples) in a pedigree and to indicate whether persons share the same household within a pedigree, regardless of the genetic relations among the individuals who share a household. However, whereas genetic relations do not change, household sharing can depend on the time of assessment of the phenotype. Notably in longitudinal studies, offspring may share a household with their parents or with their parents and siblings at the start of the study, but establish their own households later on. Here we first present an algorithm, which is available from the first author, that we developed to generate a pedigree file for all participants in the Netherlands Twin Register. Next, we used the Mendel software package (https://www.genetics.ucla.edu/ software/Mendel_current_doc.pdf) for the genetic analysis of neuroticism, specifying models that included variance components due to additive and non-additive genetic factors as well as to shared household.

\section{Methods}

\section{Participants}

Participants in the Netherlands Twin Register are young and adult twins, their biological and non-biological family members and their teachers. The Person Administration of the Netherlands Twin Register (PANTER) database is a person-oriented database that stores and specifies any number of relationships between persons (Boomsma et al. 2008). The PANTER database currently stores information on 275,250 participants. Between participants, there can be parent-offspring relationships, sibling-sibling, spouse-spouse, twin-twin and teacher-student relations. Each individual can have an unlimited number of one-toone relations with other individuals in the database. For example, multiple spouse-spouse links are possible, as are multiple father-offspring relations. A woman can have mother-offspring relations as well as teacher-pupil relations. The PANTER database stores all relations among participants, with information on whether relations are either social or biological stored in different databases. Examples of social, non-biological, relations include person A being registered as a child of person $\mathrm{B}$, while person $\mathrm{A}$ was adopted; (nearly) all spouse-spouse relations (marriages between cousins are allowed in the Netherlands); or person A being the offspring in a family where the mother married for a second time and person $\mathrm{B}$ is the second husband of A's mother, so that A and B have a parent-offspring link. In PANTER, both the first and second husbands of mother can have a parent-offspring relation with person A. Additional NTR databases contain information on pedigree relations 
from demographic databases, genotyping projects, surveys and interviews and specify information regarding the zygosity of twins and biological or social relations among family members. Zygosity information comes from blood group or DNA markers or survey data and consists of oneto-one relations describing whether co-twins are monozygotic (MZ) or dizygotic (DZ). For our study of neuroticism, all relationship types except teacher-student relations are relevant.

\section{Measures of neuroticism}

Neuroticism was assessed by the Amsterdamse Biografische Vragenlijst (ABV, Wilde 1970), and the NEO Five-Factor Inventory (NEO-FFI, Costa and McCrae 1992). The ABV was part of adolescent and adult NTR surveys collected in 1991, 93, 97, 2000 and 2002 and is a Dutch personality questionnaire that was closely modeled on the Eysenck Personality Questionnaire (EPQ). The NEO-FFI was included in adult NTR surveys collected in 2004 and 2009 and in adolescent NTR surveys (Bartels et al. 2013). Neuroticism data were harmonized to a common scale by IRT modeling (van den Berg et al. 2014). For each subject one IRT score was available and the age at which this score was measured. There were 31,152 NTR participants ( $41 \%$ male) with valid neuroticism data. Their average age when Neuroticism was assessed was $37.26(\mathrm{SD}=15.34)$ years (37.8 in men, 36.9 in women) and year of birth ranged between 1909 and 1997 (mean 1965). Twins and multiples made up $47 \%$ of the total sample. Most twins came in complete pairs (85\% of the sample), $14.4 \%$ came from incomplete pairs and the remaining were higher order multiples.

\section{Genetic analyses}

To obtain a first impression of familial resemblance for Neuroticism, correlations were estimated for MZ and DZ twin pairs, for biological sibling pairs, for father-offspring and for mother-offspring pairs. Two spouse correlations were computed: one for parents of twins and one for twins and their spouses, who on average were 17 years younger than the parents of twins. Familial correlations were obtained for independent pairs of relatives, e.g. a family with three siblings provided one sibling pair. Father-offspring and mother-offspring pairs similarly were based on selecting different twins from a pair. The $95 \%$ confidence intervals (CI) around correlations were obtained from Mx (Neale and Miller 1997). Genetic analyses, aiming at estimating total and narrow-sense heritability and the effects of sharing a household, were carried out in Mendel (Lange et al. 2013). In all analyses, age and sex were included as fixed effects. The variance of the residuals of the linear regression model was decomposed into genetic and environmental components. We estimated additive (A) and non-additive or dominance (D) genetic variance and also included variance due to shared household effects. Sharing a household was defined for all spouses living together and for parents with their offspring when the offspring was 18 years old or less. The remainder of the variance was environmental variance not shared by family members (E). Phenotypes of individuals who were not part of the same extended pedigree were assumed to be uncorrelated. We analyzed three models with different combinations of the A, D, household and $\mathrm{E}$ variance components and tested the significance of variance components due to household and non-additive genetic factors. We note that the likelihood-ratio test of a variance component does not follow the usual central $\chi^{2}(1)$ distribution under the hypothesis that the variance component is zero (Dominicus et al. 2006) and adopt the following simple procedure: we test the variance component using the standard test, recognizing that this results in an inflated type I error rate. This is problematic only if one does not reject the alternative hypothesis that the variance component is zero.

We defined a nuclear family as consisting of a male and female parent, and all known offspring who share these parents. The offspring can have their own spouses and their own offspring with their spouse. A family consists of all individuals who are known to be related in some way, and will generally consist of one nuclear family or the union of multiple nuclear families, linked through parent-child relationships, sibling-sibling relations or spouse-spouse relations. Individuals can have multiple spouses, with whom they do or do not have offspring. The relational data required for the pedigree construction were extracted from the PANTER database, in the form of a file listing all existing one-to-one relationships between individuals in the database, as well as their gender and the types of relationship (e.g. spouse-spouse, parent-offspring). The data for pedigree construction are retrieved every $24 \mathrm{~h}$ from the PANTER database. These data are then combined with other data sources, such as the zygosity database. Information on relations that are known to be non-biological is also imported from external databases and used in the pedigree buildup. Mendel's input pedigree file consists of 6 required fields per individual, plus additional fields for shared household effects, for quantitative traits and discrete variables. The six basic fields describe the family ID, the ID of the individual, the ID of the father of that person, the ID of the mother, the gender of the individual and a monozygotic twin (or higher-order MZ multiple) identifier. The MZ identifier is an ID indicating that every person with this specific identifier in the family is monozygotic with another person, or persons, sharing that identifier. All family members are grouped together in the input (Fig. 1). Household identifiers can be added as 
extra columns indicating that people with the same label in this field share a household, which may increase their phenotypic resemblance. A household indicator may specify spouse pairs, each member of a pair sharing an identifier with the spouse, with or without their offspring sharing a household, or for example specify that all twins, regardless of zygosity, or all offspring regardless of twin or non-twin status share an environmental component. Individuals are required to have either both or neither of their parents identified. To deal with missing parent-offspring relations, the creation of "dummy" parents was necessary, i.e. parents who define a nuclear family but who are not registered with the NTR. Also, the presence of more than two registered parents must be handled. More than two parents in a family occur when parents of twins divorce and then remarry. NTR has several instances where the new marriage then also has twin offspring. The algorithm for dummy-parent creation is as follows: Consider an individual called P. When $P$ is a founder (i.e. an individual without registered parents) and $\mathrm{P}$ has no siblings or all of $\mathrm{P}$ 's siblings are founders as well, create two dummy parents for P and P's siblings and co-twins. In case $\mathrm{P}$ is a founder but any of P's siblings is not, consider two different situations. In the first situation, $\mathrm{P}$ has a registered co-twin and is assigned the same parents as P's co-twin. In the second situation, P only has non-twin siblings and $\mathrm{P}$ is to be removed from the pedigree. Move on to the next individual and repeat this until all individuals have been processed. If $\mathrm{P}$ has more than two registered parents, e.g. two fathers and a mother, and it is not known which father is the biological parent, remove $\mathrm{P}$ from the pedigree and move on to the next individual. If a co-twin of $\mathrm{P}$ has parents who do not match with the parents of $\mathrm{P}$, remove $\mathrm{P}$ and move on (here we assume that two twins always share the same parents, this is not assumed for siblings). No parents need to be created for $\mathrm{P}$ if exactly two parents of opposite sex are registered for P. Finally, one dummy parent needs to be created for $\mathrm{P}$ and all of P's co-twins and biological siblings in case only one parent is registered. The approach implies that for families where we cannot establish genetic relations, e.g. from survey or other additional data, that these families are removed. When the family structure was unclear, additional data regarding complex parent-child and sibling-sibling relations were obtained from the Dutch city council administration (Gemeentelijke Basisadministratie: GBA), information was checked against the NTR genotype database and information from surveys was utilized, where NTR participants were asked about biological and social relations with other family members. We removed 135 subjects from the pedigrees for whom biological versus social relationship could not be resolved. In the pedigree construction we also removed all teachers of twins (i.e. teacher-student relations are not included).

\section{Results}

The NTR pedigree consisted of 253,015 individuals in 58,645 extended families (excluding 7201 "dummy" parents created to specify the pedigree structure). There were 14,805 MZ twin, or triplet, multiples, 6626 were male and 8179 female. The number of nuclear families in the NTR pedigree was 59,674, with the largest nuclear family consisting of 14 individuals. A nuclear family contained at most seven daughters or at most 11 sons. On average, a nuclear family contained 2.29 children, for a total of 136,737 offspring. Of these children, 69,301 were female, and 65,119 were male (for 2,307 twins and ten others sex was unknown). For the genetic analyses of neuroticism in Mendel a total of 36,639 individuals were present in a trimmed pedigree of which 31,152 were phenotyped (a large number of twin families in NTR come from the Young NTR in which phenotyping for personality is limited). The number of nuclear families with neuroticism data and with at least two family members was 7854. Table 1 describes the composition for the entire NTR pedigree and for the subset with neuroticism data. The Mendel software allowed us to analyze more the complex family structures, providing extra sources of information for heritability-related analyses beyond parents and twins. An example of a more complex family structure in the NTR pedigree is a 'double first cousin' structure. Here, two dizygotic twin pairs A1, A2 and B1, B2 were registered as spouses (i.e., A1 and B1 were registered as spouses, and A2 and B2 were registered as spouses). Both couples had offspring (one and two children respectively), so that these offspring had the same set of grandparents, even though they had different parents. There was information on 87 aunts and uncles of twins, and a large (34 members) extended pedigree where cousins of twins were also measured. This is not the largest pedigree in the set, which is one with 44 members. In total there are 514 large ( $>10$ family members) and 40 very large ( $>20$ family) pedigrees.

Table 2 summarizes correlations for neuroticism among family members. Correlations were highest for $\mathrm{MZ}$ twins (0.52), very similar for DZ and sibling pairs (0.22 and 0.20) and lower for parents and offspring (0.14 for father-offspring and 0.16 for mother-offspring). The spouse correlations in parents of twins, who were on average 52 years old, and in twins and their spouses, who on average were 35 years old, were 0.16 and 0.05 , respectively, suggesting that sharing a household for more prolonged periods of time increases resemblance for neuroticism. The pattern of familial correlations is consistent with at least three, not mutually exclusive, hypotheses: a lower parent-offspring than sibling correlation is expected when genetic dominance contributes to phenotype variation (Lynch and Walsh (1998). Second, this pattern of resemblance is also expected under genotype by age interaction and, thirdly 
Table 1 Number of registered individuals in the Netherlands (excluding teachers ${ }^{\mathrm{a}}$ )
Table 2 Basic summary of familial correlations and their confidence intervals for neuroticism

\begin{tabular}{|c|c|c|}
\hline & NTR pedigrees & Neuroticism pedigrees \\
\hline Number of extended families & 58,645 & 9527 \\
\hline Individuals & 253,015 registered & $36,639(31,152$ phenotyped $)$ \\
\hline MZ male (individuals) & 13,268 & 2451 \\
\hline MZ female (individuals) & 16,387 & 4904 \\
\hline MZ (individuals ${ }^{\mathrm{b}}$ ) & 29,657 & 7355 \\
\hline DZ male (individuals) & 33,860 & 3163 \\
\hline DZ female (individuals) & 33,659 & 4625 \\
\hline DZ (individuals) & 67,519 & 7788 \\
\hline Unknown zygosity male (individuals) & 10,402 & 192 \\
\hline Unknown zygosity female (individuals) & 10,588 & 390 \\
\hline Unknown zygosity (individuals ${ }^{\mathrm{c}}$ ) & 23,297 & 582 \\
\hline Fathers & 57,010 & 5678 \\
\hline Mothers & 57,872 & 5992 \\
\hline Parents ${ }^{\mathrm{d}}$ & 114,882 & 11,670 \\
\hline Brothers & 7214 & 1586 \\
\hline Sisters & 8369 & 2811 \\
\hline Full sibs (non-twin individuals ${ }^{\mathrm{e}}$ ) & 15,589 & 4397 \\
\hline Half-brothers & 167 & 29 \\
\hline Half-sisters & 176 & 54 \\
\hline Half-sibs (non-twin individuals ${ }^{\mathrm{f}}$ ) & 343 & 83 \\
\hline Spouse pairs with offspring ${ }^{\mathrm{g}}$ & 56,795 pairs & 5550 pairs \\
\hline Spouse pairs without offspring ${ }^{\mathrm{h}}$ & 3089 pairs & 2556 pairs \\
\hline
\end{tabular}

Bold numbers represent the total number of $\mathrm{MZ}$ and DZ twins, parents, sibs and half-sibs

${ }^{a}$ NTR also includes 21,478 teachers who provide data on twins; 622 double registrations and 135 individuals for whom the biological parents cannot be resolved. These were removed from the pedigree

${ }^{\mathrm{b}}$ Includes $2 \mathrm{MZ}$ transgender individuals

${ }^{c}$ Includes 2307 individuals of unknown gender

${ }^{\mathrm{d}}$ Parents: individuals with at least one offspring (7201 dummy parents are not counted)

${ }^{\mathrm{e}}$ Six siblings of unknown sex

${ }^{\mathrm{f}}$ Half sibs: all individuals who (pairwise) share one biological parent; e.g. families with twins and one-halfsib are counted as one; families twins, one-half-sib en two full sibs are counted as three

${ }^{g}$ Spouse pairs with offspring: two persons with at least one offspring (dummy parents excluded)

${ }^{\mathrm{h}}$ Spouse pairs without offspring: spouses without registered offspring or parents

\begin{tabular}{lllll}
\hline & $\begin{array}{l}\text { N Complete } \\
\text { pairs }\end{array}$ & Correlation & 95 CI & Average age \\
\hline MZ twins & 2984 & .523 & $.499-.545$ & 30.1 \\
DZ twins & 3121 & .216 & $.182-.248$ & 27.2 \\
Siblings & 596 & .198 & $.120-.271$ & 38.3 \\
Father-twin1 & 3580 & .143 & $.111-.174$ & $53.5 / 23.6$ (father/twin) \\
Mother-twin2 & 4232 & .163 & $.133-.191$ & $51.6 / 23.6$ (mother/twin) \\
Parents of twins & 3847 & .162 & $.131-.192$ & $53.3 / 51.4$ (father/mother) \\
Twin-spouse & 1845 & .053 & $.007-.098$ & $34.6 / 35.6$ (twin/spouse) \\
\hline
\end{tabular}

if there would be household by age interaction. However, only the first hypothesis is consistent with a difference between $\mathrm{MZ}$ and $\mathrm{DZ}$ correlations that is larger than twice the correlation in DZ pairs, which is the pattern observed in the data.
The hypothesis of genotype by age interaction would be consistent with parents and offspring who differ more in age being less similar in their neuroticism scores than parents and offspring who are closer in age. We computed the differences in age between parents and offspring at the age 
at which they completed a neuroticism survey and the difference in their neuroticism scores. Distributions of these difference scores are given in the appendix. The average age difference for the father-offspring pairs was 29.8 years and for mother-offspring 28.1 years, with a substantial spread in age-difference scores in both groups. Parent-offspring pairs who did not differ by age when they completed the survey reflect those pairs in which father completed a neuroticism survey in e.g. 1991 and his son or daughter in 2013, both at the age of 22 years. The oldest age at birth of offspring was 53 for fathers and 43 years for mothers. There was no correlation between age-difference and neuroticism-difference scores in father-offspring pairs $(\mathrm{r}=-0.014, \mathrm{p}=.39)$, and a small negative correlation in mother-offspring pairs $(r=-0.068, p<.00)$, i.e. larger age differences were associated with smaller differences in neuroticism, which seems not compatible with a genotype age interaction effect. The analysis was repeated in 514 sibling pairs, whose average age difference when the completing the neuroticism questionnaire was 4.02 years $(\mathrm{SD}=3.30)$, with the largest age difference being 27 years. No correlation was seen in the sibling group between age-difference and neuroticism-difference scores $(r=0.007, p=.87)$. The shared household by age interaction hypothesis was explored by looking at parent-offspring correlations in families with offspring ages 18 years or younger versus parent-offspring correlations in families with offspring over 18 years. For father with offspring the correlation was $0.20(0.13-0.27)$ in 605 families with offspring 18 years or younger, and $0.13(0.09-0.16)$ in 2975 families with offspring over 18 years. For mother-offspring, the correlation was $0.19(0.12-0.25)$ in 768 families with offspring 18 years or below, and $0.16(0.13-0.19)$ for offspring over 18 years from 3464 families. This pattern is consistent with younger children, sharing a household with their parents, resembling their parents more, but CI in the younger group are relatively large. For $\mathrm{MZ}$ and $\mathrm{DZ}$ twins a similar breakdown of correlations by age was done, i.e. twin correlations were estimated for pairs aged 18 years or younger versus pairs over 18 years. In $\mathrm{MZ}$ twins $(\mathrm{N}=383$ pairs for twins 18 or younger and 2601 pairs over 18$)$ the correlations were $0.53(0.46-0.59)$ and $0.52(0.49-0.54)$. In DZ pairs $(\mathrm{N}=489$ pairs for twins 18 or younger and 2632 pairs over 18) the correlations were $0.26(0.18-0.34)$ and $0.20(0.17-0.24)$, consistent with younger pairs showing a somewhat larger resemblance.

The mean IRT neuroticism score was $0.08(\mathrm{SD}=0.98)$ with values ranging from -3.43 to 4.28 . There was a small negative correlation of age and neuroticism of -0.076 . There was an effect of sex on neuroticism with women scoring 0.4 standard deviations higher on average than men. In this large sample, both effects are highly significant. The additive genetic, non-additive genetic (dominance) and shared household variance component estimates and their standard errors are given in Table 3, along with the loglikelihood (LL) for each model. Compared to estimates, the standard errors are small, indicating that the additive genetic and dominance components estimates were significant as was the effect of a shared household. Removing either the shared household effect or the dominance effect introduced a worsening of fit.

\section{Discussion}

Based on the analysis of neuroticism data in $>30,000$ individuals, we conclude that variation in neuroticism is in part explained by genetic influences. Additive and non-additive genetic factors are likely to both contribute to variation and explained respectively 27 and $20 \%$ of the total phenotypic variance, i.e. the narrow-sense heritability for neuroticism was $27 \%$ and the broad-sense heritability $47 \%$. These estimates were stable under different model specifications, that is, the estimates hardly changed when omitting the significant shared household effect from the model. Genetics of Personality Consortium et al. (2015) estimated in a Dutch subgroup from this cohort with neuroticism and genomewide single nucleotide polymorphism (SNP) data that 14.7\% of the variance in neuroticism was explained by SNPs (CI

Table 3 Parameter estimates (and SE) for variance components

\begin{tabular}{clllllll}
\hline Model & $\begin{array}{l}\text { Log-likeli- } \\
\text { hood }\end{array}$ & $\begin{array}{l}\text { Additive } \\
\text { genetic vari- } \\
\text { ance }\end{array}$ & $\begin{array}{l}\text { Dominance } \\
\text { genetic vari- } \\
\text { ance }\end{array}$ & $\begin{array}{l}\text { Shared house- } \\
\text { hold variance }\end{array}$ & $\begin{array}{l}\text { Non-genetic } \\
(\text { E) variance }\end{array}$ & $\begin{array}{l}\text { Heritability (additive } \\
\text { and dominance) }\end{array}$ & Household $^{\text {a }}$ \\
\hline $\begin{array}{c}\text { ADE plus } \\
\text { household }\end{array}$ & -13390.40 & $\begin{array}{c}0.2449 \\
(0.0145)\end{array}$ & $\begin{array}{c}0.1822 \\
(0.0175)\end{array}$ & $\begin{array}{c}0.1210 \\
(0.0100)\end{array}$ & $\begin{array}{c}0.3656 \\
(0.0135)\end{array}$ & $0.4271 / 0.9137=0.4674$ & $0.1210 / 0.9137=0.1324$ \\
$\begin{array}{c}\text { ADE no } \\
\text { household }\end{array}$ & -13464.28 & $\begin{array}{c}0.2455 \\
(0.0134)\end{array}$ & $\begin{array}{c}0.1912 \\
(0.0168)\end{array}$ & - & $\begin{array}{c}0.4761 \\
(0.0109)\end{array}$ & $0.4367 / 0.9128=0.4784$ & - \\
$\begin{array}{c}\text { AE plus } \\
\text { household }\end{array}$ & -13446.34 & $\begin{array}{c}0.3454 \\
(0.0111)\end{array}$ & - & $\begin{array}{c}0.1270 \\
(0.0098)\end{array}$ & $\begin{array}{c}0.4460 \\
(0.0129)\end{array}$ & $0.3454 / 0.9184=0.3761$ & $0.1270 / 0.9184=0.1383$ \\
\hline
\end{tabular}

Heritability and household columns give the proportion of variance explained by total genetic and household effects

${ }^{a}$ All spouses and their offspring aged 18 years or less 
0.2-29\%). In the UK Biobank data (Smith et al. 2016), where EPQ-Neuroticism was assessed in $>90,000$ subjects, a SNP-based heritability estimate for neuroticism of $\sim 15 \%$ $(\mathrm{SE}=0.7 \%$ ) was reported and in a publication by Lo et al. (2017) in nearly 60,000 participants from 23 and me, the SNP heritability was $12 \%$ (CI 8.7-15\%). These estimates account for additive genetic variance and based on our estimate of $27 \%$ for narrow-sense heritability, the SNP-based estimates thus capture around $50 \%$ of the additive genetic variance in neuroticism.

Often the analysis of pedigree data is limited to estimation of the additive genetic (A) and unique environmental (E) variance components (Docherty et al. 2015). In contrast, twin researchers often explicitly consider common environmental effects, while recognizing that the classical twin design does not allow simultaneous estimation of common environmental (C) and genetic dominance variance (D) components. Keller et al. (2010) observed that increasingly complex extended twin family designs produce more accurate results, and are less sensitive to violations of model assumptions than simpler models. They concluded that researchers interested in characterizing the environment or the composition of genetic variance should use extended designs when possible. Here we used all information on neuroticism from twins and their family members, including distant relatives, and estimated a significant contribution of shared household environment in the presence of genetic dominance. We should note that a shared household effect does not capture the same effects that may be included when modeling common environment in the classical twin design. For example it does not account for any persistent effects of shared environment on resemblance among relatives. We explored alternative definitions of 'household sharing' including sharing defined as true when a household was ever shared, household sharing for all siblings including twins and household sharing for twins only. None of these models described the data better than the immediate household definition (shared only when the household is shared at the time of the neuroticism assessment), indicating that persistent shared environment is less likely. Lake et al. (2000) previously analyzed data on neuroticism in extended twin kinships among 45,850 family members from Australia and the United States. Their estimate of broad sense heritability was nearly identical to the estimate obtained in our sample from the Netherlands. However, rather than modeling a household effect of relatives living together, Lake et al. considered the effects of assortative mating and vertical environmental transmission, which will lead to a shared sibling environment. They found that assortative mating was too small to have a substantial effect on the correlation between relatives. In Mendel it is not possible
Fig. 1 Specification of relations among NTR participants in the PANTER database for a nuclear family of two parents with MZ twin boys, below the specification of this pedigree in the MENDEL input file

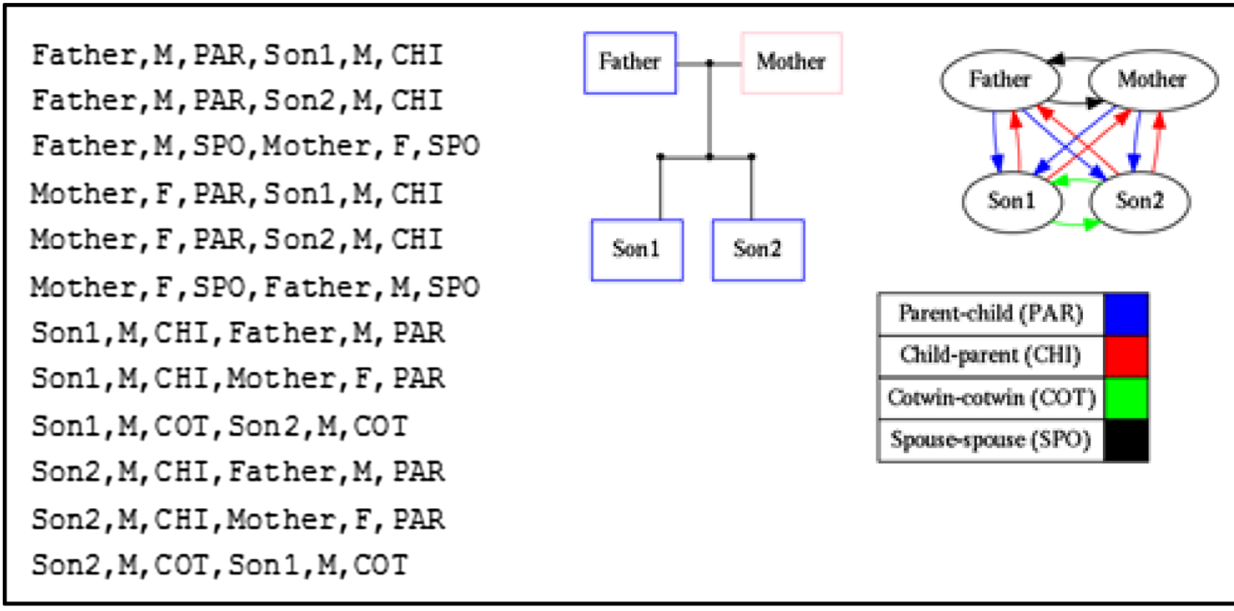

111, Father, ,, $M$, ,

111, Mother,,, $F_{,}$,

111, Son1, Father, Mother, M, T1,

111, Son2, Father, Mother, M,T1,

$111=$ family ID

$\mathrm{T} 1=$ twin code for $\mathrm{MZ}$ 
to model and test for the genetic effects of phenotypic assortative mating. We explored if marital cohabitation might explain spousal resemblance and found support for this when comparing younger and older couples. Lake et al. also concluded that there was no evidence for vertical environmental transmission. The estimate of $13 \%$ explained variance by shared household in the Dutch data does not primarily arise from vertical transmission and is based on the similarity among spouses, parents and their offspring of $<18$ years, as well as siblings and twins under 18 years, who live together in the same household. For a phenotype related to neuroticism, Dolan et al. (2014) obtained support for the effect of one twin's phenotype on the other twin's environment in a longitudinal analysis of childhood anxiety. That is, the anxious behavior of one twin contributed to the environment of the co-twin. This process gives rise to genotype-environment covariance, which may produce apparent shared environmental influences, if it is not explicitly modeled. This process is not limited to twins, i.e., the behavior or personality of any family member may contribute to the environment of his or her cohabitants and such covariance between additive genetic and household effects will also contribute to a household effect (Purcell 2002) if it is not modeled. We therefore realize that household effect may in part be attributable to other process other than the simple main effects of 'true' shared environment. Within individuals, high neuroticism scores are a risk factor for depression, which is supported by the prediction of major depressive disorder by polygenic neuroticism scores (Genetics of Personality Consortium et al. 2015), and high genetic correlations of neuroticism and depression (Gale et al. 2016; Okbay et al. 2016; Lo et al. 2017). It is possible that not only one's own neuroticism, but also neuroticism in family members with whom an individual shares a household constitutes a risk factor for depression. To aid in exploring such scenario's and resolve the interpretation of genetic correlations and causation at multiple explanatory levels, phenotype and genotype data not only from individuals but also from those with whom they share a household or a broader environment are required (e.g., Nivard and Boomsma 2016).
Funding HN was supported by Royal Netherlands Academy of Science Professor Award (PAH/6635) to DIB, and by a University Research Fellow (URF) of the Vrije Universiteit, Amsterdam. Data collection and zygosity typing were made possible by multiple grants from the Netherlands Organization for Scientific Research (NWO): 575-25-006, 480-04-004, 904-61-090, 904-61-193, 400-05-717, 31160008, SPI 56-464-14192 and the Avera Institute for Human Genetics. We gratefully acknowledge grant NWO 480-15-001/674: Netherlands Twin Registry Repository: researching the interplay between genome and environment.

\section{Compliance with ethical etandards}

Conflict of interest Dorret I. Boomsma, Quinta Helmer, Harold A. Nieuwboer, Jouke Jan Hottenga, Marleen H. de Moor, Stéphanie M. van den Berg, Gareth E. Davies, Jacqueline M. Vink, Maarten J. Schouten, Conor V. Dolan, Gonneke Willemsen, Meike Bartels, Toos C. E. M. van Beijsterveldt, Lannie Ligthart, Eco J de Geus declare that they have no conflict of interest.

Ethical approval All procedures performed in studies involving human participants were in accordance with the ethical standards of the institutional and/or national research committee and with the 1964 Helsinki declaration and its later amendments or comparable ethical standards. The studies were approved by the Central Ethics Committee on Research Involving Human Subjects of the VU University Medical Center, Amsterdam, an Institutional Review Board certified by the U.S. Office of Human Research Protections (IRB number IRB-2991 under Federal-wide Assurance-3703; IRB/institute codes, NTR 03-180).

Informed consent Informed consent was obtained from all individual participants included in the study.

Open Access This article is distributed under the terms of the Creative Commons Attribution 4.0 International License (http://creativecommons.org/licenses/by/4.0/), which permits unrestricted use, distribution, and reproduction in any medium, provided you give appropriate credit to the original author(s) and the source, provide a link to the Creative Commons license, and indicate if changes were made.

\section{Appendix}

Distribution of age differences between father-offspring and mother-offspring for the age at which the neuroticism survey was completed and distribution of differences in neuroticism scores. 

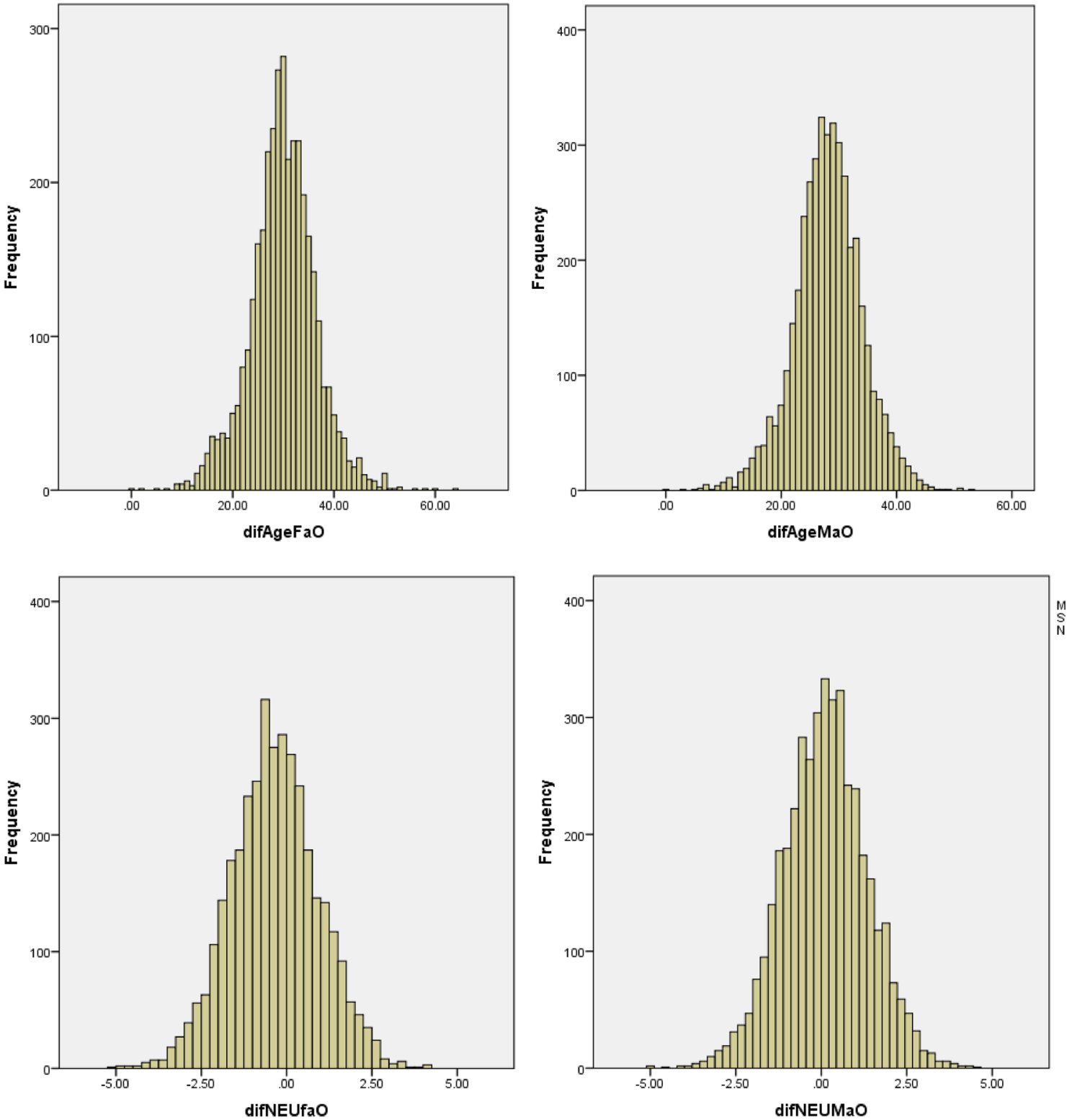

\section{References}

Abecasis GR, Cherny SS, Cookson WO, Cardon LR (2002) Merlinrapid analysis of dense genetic maps using sparse gene flow trees. Nat Genet 30(1):97-101

Bartels M, Cacioppo JT, van Beijsterveldt TC, Boomsma DI (2013) Exploring the association between well-being and psychopathology in adolescents. Behav Genet 43(3):177-190

Boomsma DI, Willemsen G, Vink JM, Bartels M, Groot P, Hottenga JJ, van Beijsterveldt CE, Stroet T, van Dijk R, Wertheim R, Visser M, van der Kleij F (2008) Design and implementation of a twinfamily database for behavior genetics and genomics studies. Twin Res Hum Genet 11(3):342-348

Costa PT, McCrae RR (1992) Professional manual: revised neo personality inventory (Neo-PI-R) and neo five- factor-inventory (NeoFFI). Psychological Assessment Resources, Odessa

Docherty AR, Kremen WS, Panizzon MS, Prom-Wormley EC, Franz CE, Lyons MJ, Eaves LJ, Neale MC (2015) Comparison of twin and extended pedigree designs for obtaining heritability estimates. Behav Genet 45(4):461-466

Dolan CV, de Kort JM, van Beijsterveldt TC, Bartels M, Boomsma DI (2014) GE covariance through phenotype to environment transmission: an assessment in longitudinal twin data and application to childhood anxiety. Behav Genet 44(3):240-253

Dominicus A, Skrondal A, Gjessing HK, Pedersen NL, Palmgren J (2006) Likelihood ratio tests in behavioral genetics: problems and solutions. Behav Genet 36(2):331-340

Gale CR, Hagenaars SP, Davies G, Hill WD, Liewald DC, Cullen B, Penninx BW; International Consortium for Blood Pressure GWAS, CHARGE Consortium Aging and Longevity Group, Boomsma DI, Pell J, McIntosh AM, Smith DJ, Deary IJ, Harris SE (2016) Pleiotropy between neuroticism and physical and 
mental health: findings from 108038 men and women in UK Biobank. Transl Psychiatry 6:e791

Genetics of Personality Consortium, de Moor MH, van den Berg SM, Verweij KJ, Krueger RF, Luciano M, Arias Vasquez A, Matteson LK, Derringer J, Esko T, Amin N, Gordon SD, Hansell NK, Hart AB, Seppälä I, Huffman JE, Konte B, Lahti J, Lee M, Miller M, Nutile T, Tanaka T, Teumer A, Viktorin A, Wedenoja J, Abecasis GR, Adkins DE, Agrawal A, Allik J, Appel K, Bigdeli TB, Busonero F, Campbell H, Costa PT, Davey Smith G, Davies G, de Wit H, Ding J, Engelhardt BE, Eriksson JG, Fedko IO, Ferrucci L, Franke B, Giegling I, Grucza R, Hartmann AM, Heath AC, Heinonen K, Henders AK, Homuth G, Hottenga JJ, Iacono WG, Janzing J, Jokela M, Karlsson R, Kemp JP, Kirkpatrick MG, Latvala A, Lehtimäki T, Liewald DC, Madden PA, Magri C, Magnusson PK, Marten J, Maschio A, Medland SE, Mihailov E, Milaneschi Y, Montgomery GW, Nauck M, Ouwens KG, Palotie A, Pettersson E, Polasek O, Qian Y, Pulkki-Råback L, Raitakari OT, Realo A, Rose RJ, Ruggiero D, Schmidt CO, Slutske WS, Sorice R, Starr JM, St Pourcain B, Sutin AR, Timpson NJ, Trochet $\mathrm{H}$, Vermeulen S, Vuoksimaa E, Widen E, Wouda J, Wright MJ, Zgaga L, Porteous D, Minelli A, Palmer AA, Rujescu D, Ciullo M, Hayward C, Rudan I, Metspalu A, Kaprio J, Deary IJ, Räikkönen K, Wilson JF, Keltikangas-Järvinen L, Bierut LJ, Hettema JM, Grabe HJ, van Duijn CM, Evans DM, Schlessinger D, Pedersen NL, Terracciano A, McGue M, Penninx BW, Martin NG, Boomsma DI (2015) Meta-analysis of genome-wide association studies for neuroticism, and the polygenic association with major depressive disorder. JAMA Psychiatry. 72(7):642-650

Jöreskog KG (1970) A general method for analysis of covariance structures. Biometrika 57:239-251

Keller MC, Medland SE, Duncan LE (2010) Are extended twin family designs worth the trouble? A comparison of the bias, precision, and accuracy of parameters estimated in four twin family models. Behav Genet 40(3):377-393

Lake RI, Eaves LJ, Maes HH, Heath AC, Martin NG (2000) Further evidence against the environmental transmission of individual differences in neuroticism from a collaborative study of 45,850 twins and relatives on two continents. Behav Genet 30(3):223-233

Lange K, Papp JC, Sinsheimer JS, Sripracha R, Zhou H, Sobel EM (2013) Mendel: the Swiss army knife of genetic analysis programs. Bioinformatics 29(12):1568-1570

Lo MT, Hinds DA, Tung JY, Franz C, Fan CC, Wang Y, Smeland OB, Schork A, Holland D, Kauppi K, Sanyal N, Escott-Price V, Smith DJ, O'Donovan M, Stefansson H, Bjornsdottir G, Thorgeirsson TE, Stefansson K, McEvoy LK, Dale AM, Andreassen OA, Chen CH (2017) Genome-wide analyses for personality traits identify six genomic loci and show correlations with psychiatric disorders. Nat Genet 49(1):152-156

Lynch M, Walsh (1998). Genetics and analysis of quantitative traits. Sinauer Asscoiates, Inc., Sunderland

Middeldorp CM, de Geus EJ, Beem AL, Lakenberg N, Hottenga JJ, Slagboom PE, Boomsma DI (2007) Family based association analyses between the serotonin transporter gene polymorphism (5-HTTLPR) and neuroticism, anxiety and depression. Behav Genet 37(2):294-230

Muthén B, Asparouhov T, Rebollo I (2006) Advances in behavioral genetics modeling using Mplus: applications of factor mixture modeling to twin data. Twin Res Hum Genet 9(3):313-324

Neale MC, Miller MB (1997) The use of likelihood-based confidence intervals in genetic models. Behav Genet 27(2):113-120

Neale MC, Walters EE, Eaves LJ, Maes HH, Kendler KS (1994) Multivariate genetic analysis of twin-family data on fears: Mx models. Behav Genet 24(2):119-139

Neale MC, Hunter MD, Pritikin JN, Zahery M, Brick TR, Kirkpatrick RM, Estabrook R, Bates TC, Maes HH, Boker SM (2016)
OpenMx 2.0: extended structural equation and statistical modeling. Psychometrika 81(2):535-549

Nivard MG, Boomsma DI (2016) Genetics: from molecule to society. Curr Biol 26(22):R1194-R1196

Nivard MG, Middeldorp CM, Dolan CV, Boomsma DI (2015) Genetic and environmental stability of neuroticism from adolescence to adulthood. Twin Res Hum Genet 18(6):746-775

Okbay A, Baselmans BM, De Neve JE, Turley P, Nivard MG, Fontana MA, Meddens SF, Linnér RK, Rietveld CA, Derringer J, Gratten J, Lee JJ, Liu JZ, de Vlaming R, Ahluwalia TS, Buchwald J, Cavadino A, Frazier-Wood AC, Furlotte NA, Garfield V, Geisel MH, Gonzalez JR, Haitjema S, Karlsson R, van der Laan SW, Ladwig KH, Lahti J, van der Lee SJ, Lind PA, Liu T, Matteson L, Mihailov E, Miller MB, Minica CC, Nolte IM, Mook-Kanamori D, van der Most PJ, Oldmeadow C, Qian Y, Raitakari O, Rawal R, Realo A, Rueedi R, Schmidt B, Smith AV, Stergiakouli E, Tanaka T, Taylor K, Wedenoja J, Wellmann J, Westra HJ, Willems SM, Zhao W, LifeLines Cohort Study, Amin N, Bakshi A, Boyle PA, Cherney S, Cox SR, Davies G, Davis OS, Ding J, Direk N, Eibich P, Emeny RT, Fatemifar G, Faul JD, Ferrucci L, Forstner A, Gieger C, Gupta R, Harris TB, Harris JM, Holliday EG, Hottenga JJ, De Jager PL, Kaakinen MA, Kajantie E, Karhunen V, Kolcic I, Kumari M, Launer LJ, Franke L, Li-Gao R, Koini M, Loukola A, Marques-Vidal P, Montgomery GW, Mosing MA, Paternoster L, Pattie A, Petrovic KE, Pulkki-Råback L, Quaye L, Räikkönen K, Rudan I, Scott RJ, Smith JA, Sutin AR, Trzaskowski M, Vinkhuyzen AE, Yu L, Zabaneh D, Attia JR, Bennett DA, Berger K, Bertram L, Boomsma DI, Snieder H, Chang SC, Cucca F, Deary IJ, van Duijn CM, Eriksson JG, Bültmann U, de Geus EJ, Groenen PJ, Gudnason V, Hansen T, Hartman CA, Haworth CM, Hayward C, Heath AC, Hinds DA, Hyppönen E, Iacono WG, Järvelin MR, Jöckel KH, Kaprio J, Kardia SL, KeltikangasJärvinen L, Kraft P, Kubzansky LD, Lehtimäki T, Magnusson PK, Martin NG, McGue M, Metspalu A, Mills M, de Mutsert R, Oldehinkel AJ, Pasterkamp G, Pedersen NL, Plomin R, Polasek O, Power C, Rich SS, Rosendaal FR, den Ruijter HM, Schlessinger D, Schmidt H, Svento R, Schmidt R, Alizadeh BZ, Sørensen TI, Spector TD, Steptoe A, Terracciano A, Thurik AR, Timpson NJ, Tiemeier H, Uitterlinden AG, Vollenweider P, Wagner GG, Weir DR, Yang J, Conley DC, Smith GD, Hofman A, Johannesson M, Laibson DI, Medland SE, Meyer MN, Pickrell JK, Esko T, Krueger RF, Beauchamp JP, Koellinger PD, Benjamin DJ, Bartels M, Cesarini D (2016) Genetic variants associated with subjective well-being, depressive symptoms, and neuroticism identified through genome-wide analyses. Nat Genet 48(6):624-633

Posthuma D, Boomsma DI (2000) A note on the statistical power in extended twin designs. Behav Genet 30(2):147-158

Purcell S (2002) Variance components models for gene-environment interaction in twin analysis. Twin Res 5(6):554-571

Rebollo I, Boomsma DI (2006a) Genetic and environmental influences on type A behavior pattern: evidence from twins and their parents in the Netherlands Twin Register. Psychosom Med 68(3):437-442

Rebollo I, Boomsma DI (2006b) Genetic analysis of anger: genetic dominance or competitive sibling interaction. Behav Genet 36(2):216-228

Smith DJ, Escott-Price V, Davies G, Bailey ME, Colodro-Conde L, Ward J, Vedernikov A, Marioni R, Cullen B, Lyall D, Hagenaars SP, Liewald DC, Luciano M, Gale CR, Ritchie SJ, Hayward C, Nicholl B, Bulik-Sullivan B, Adams M, Couvy-Duchesne B, Graham N, Mackay D, Evans J, Smith BH, Porteous DJ, Medland SE, Martin NG, Holmans P, McIntosh AM, Pell JP, Deary IJ, O'Donovan MC (2016). Genome-wide analysis of over 106000 individuals identifies 9 neuroticism-associated loci. Mol Psychiatry. 21(6):749-757 
Van den Berg SM, Glas CA, Boomsma DI (2007) Variance decomposition using an IRT measurement model. Behav Genet 37(4):604-616

Van den Berg SM, de Moor MH, McGue M, Pettersson E, Terracciano A, Verweij KJ, Amin N, Derringer J, Esko T, van Grootheest G, Hansell NK, Huffman J, Konte B, Lahti J, Luciano M, Matteson LK, Viktorin A, Wouda J, Agrawal A, Allik J, Bierut L, Broms U, Campbell H, Smith GD, Eriksson JG, Ferrucci L, Franke B, Fox JP, de Geus EJ, Giegling I, Gow AJ, Grucza R, Hartmann AM, Heath AC, Heikkilä K, Iacono WG, Janzing J, Jokela M, Kiemeney L, Lehtimäki T, Madden PA, Magnusson PK, Northstone K, Nutile T, Ouwens KG, Palotie A, Pattie A, Pesonen AK, Polasek O, Pulkkinen L, Pulkki-Råback L, Raitakari OT, Realo A, Rose RJ, Ruggiero D, Seppälä I, Slutske WS, Smyth DC, Sorice R, Starr JM, Sutin AR, Tanaka T, Verhagen J, Vermeulen S, Vuoksimaa E, Widen E, Willemsen G, Wright MJ, Zgaga L, Rujescu D, Metspalu A, Wilson JF, Ciullo M, Hayward C, Rudan I, Deary IJ,
Räikkönen K, Arias Vasquez A, Costa PT, Keltikangas-Järvinen L, van Duijn CM, Penninx BW, Krueger RF, Evans DM, Kaprio J, Pedersen NL, Martin NG, Boomsma DI (2014) Harmonization of neuroticism and extraversion phenotypes across inventories and cohorts in the genetics of personality consortium: an application of item response theory. Behav Genet 44(4):295-313

Vukasović T, Bratko D (2015) Heritability of personality: a metaanalysis of behavior genetic studies. Psychol Bull 141(4):769-785

Weir BS, Anderson AD, Hepler AB (2006) Genetic relatedness analysis: modern data and new challenges. Nat Rev Genet 7(10):771-780

Weiss K (1993) Genetic variation and human disease. Principles and evolutionary approaches. Cambridge Univ. Press, Cambridge

Wilde GJS (1970) Neurotische labiliteit gemeten volgens de vragenlijstmethode (The questionnaire method as a means of measuring neurotic instability). Van Rossen, Amsterdam 